\title{
PRODUÇÃO E REPRODUÇÃO DO ESPAÇO URBANO NA REGIÃO METROPOLITANA DE GOIÂNIA: Dispersão Urbana e o Vetor de Expansão à Sudeste
}

\author{
Autor: Lorena Cavalcante Brito, Celene Cunha Monteiro Antunes Barreira, Erika Cristine Kneib \\ Instituição: Universidade Federal de Goiás (UFG), Instituto de Estudos Socioambientais (IESA), Programa \\ de Pós-Graduação em Geografia (PPGeo) \\ Orientador: Celene Cunha Monteiro Antunes Barreira \\ Co-orientador: Erika Cristine Kneib \\ E-mail: lorena@lorenacavalcante.com
}

\section{RESUMO}

Discute o processo de metropolização da cidade de Goiânia, sob o viés dos instrumentos de gestão, a partir de um estudo de caso aplicado ao Vetor de Expansão à Sudeste da Capital do Centro-Oeste brasileiro. São analisados os fatores que possibilitaram o encontro do vetor com o município vizinho em decorrência do processo de metropolização da cidade por conurbação e, simultaneamente, do processo de abandono das áreas centrais, por parte da elite. O recorte espaço-temporal estudado, do início da desestruturação do tecido urbano da Região Sudeste à década atual (2000-2020), é marcado por várias fases que, por vezes, exemplificam a própria história de expansão de Goiânia, permitindo o seu amplo e detalhado conhecimento. O que por sua vez possibilita a compreensão da dinâmica de ocupação dos condomínios fechados de alta renda na cidade de Goiânia em sua totalidade, bem como a sua atual tendência de dispersão urbana.

\section{PALAVRAS-CHAVE}

Região Metropolitana de Goiânia. Planejamento Urbano. Instrumentos de Gestão. Dispersão Urbana.

\begin{abstract}
It discusses the process of metropolization of the city of Goiânia, under the bias of the management instruments, based on a case study applied to the Expansion Vector to the Southeast of the Brazilian Central-West Capital. We analyze the factors that allowed the meeting of the vector with the neighboring municipality as a result of the metropolitanization process of the city by conurbation and, simultaneously, the process of abandonment of the central areas by the elite. The studied space-time clash, from the beginning of the disintegration of the urban fabric of the Southeast Region to the present decade (2000-2020), is marked by several phases that sometimes exemplify Goiânia's own expansion history, allowing its wide and detailed knowledge. This, in turn, makes it possible to understand the dynamics of occupation of the closed condominiums of high income in the city of Goiânia in its totality, as well as its current tendency of urban dispersion.
\end{abstract}

\section{KEYWORDS}

Metropolitan Region of Goiânia. Urban Planning. Management Instruments. Urban dispersion. 


\section{INTRODUÇÃO}

Goiânia, capital do estado de Goiás, é uma cidade de 84 anos, alçada em 1999 à condição de metrópole, contando com uma população estimada em 2.346.610 habitantes (IMB, 2017). Institucionalizada de fato pela Lei Complementar oㅡ 27 de 30 de dezembro de 1999, a Região Metropolitana de Goiânia foi alterada pelas Leis Complementares ํo 78 de 25 de março de 2010 e ํo 87 de 07 de julho de 2011. Atualmente é constituída por 20 Municípios (figura 1): Abadia de Goiás, Aparecida de Goiânia, Aragoiânia, Bela Vista de Goiás, Bonfinópolis, Brazabrantes, Caldazinha, Caturaí, Goianápolis, Goiânia, Goianira, Guapó, Hidrolândia, Inhumas, Nerópolis, Nova Veneza, Santo Antônio de Goiás, Senador Canedo, Terezópolis de Goiás e Trindade.

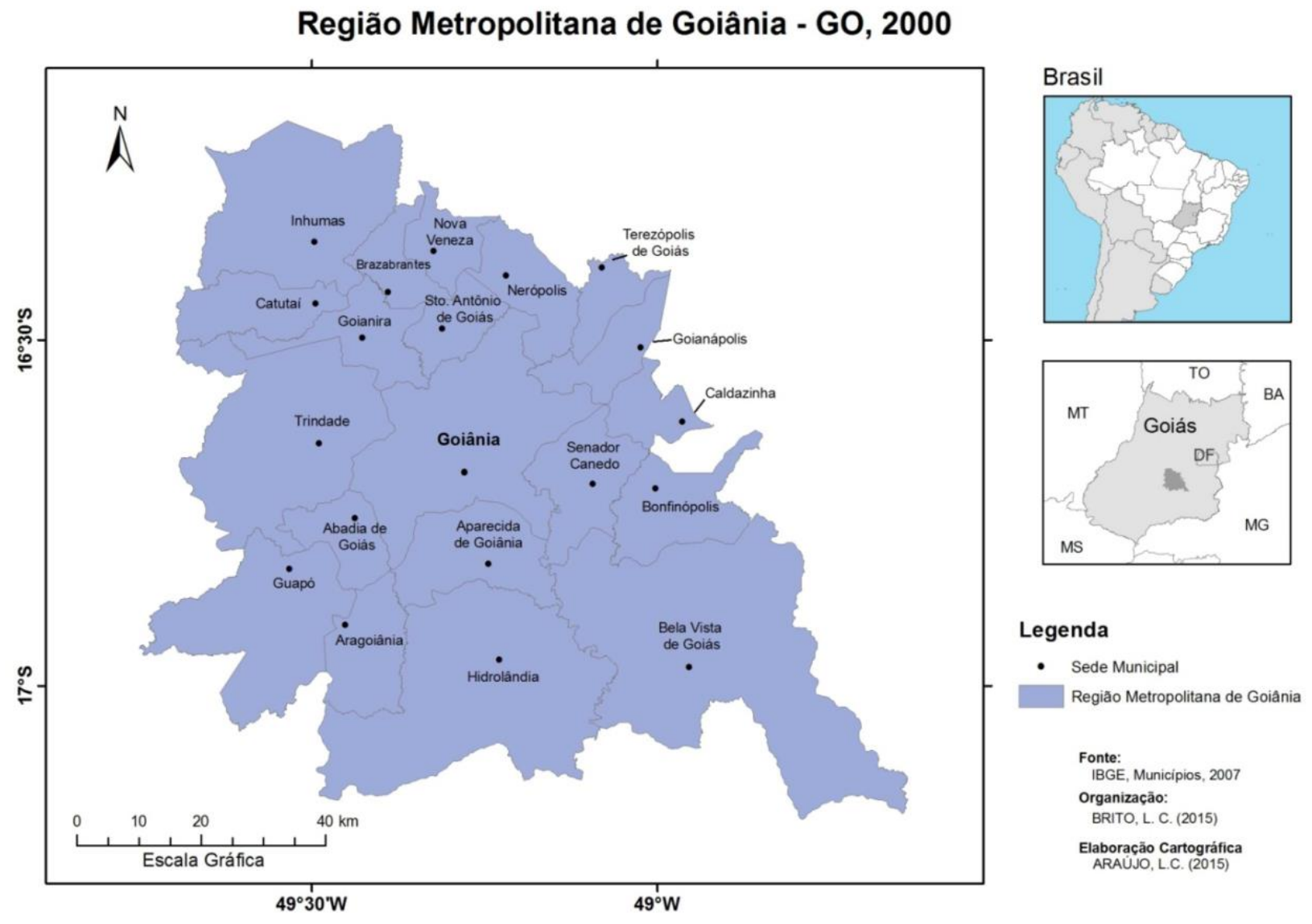

Figura 1 - Região Metropolitana de Goiânia na década de 2000. Fonte: BRITO (2015).

Goiânia, capital do estado de Goiás, é uma cidade de 84 anos, alçada em 1999 à condição de metrópole, contando com uma população estimada em 2.346.610 habitantes (IMB, 2013). Institucionalizada de fato pela Lei Complementar oㅡ 27 de 30 de dezembro de 1999, a Região Metropolitana de Goiânia foi alterada pelas Leis Complementares ํo 78 de 25 de março de 2010 e o 87 de 07 de julho de 2011. Atualmente é constituída por 20 Municípios (figura 1): Abadia de Goiás, Aparecida de Goiânia, Aragoiânia, Bela Vista de Goiás, Bonfinópolis, Brazabrantes, Caldazinha, Caturaí, Goianápolis, Goiânia, Goianira, Guapó, Hidrolândia, Inhumas, Nerópolis, Nova Veneza, Santo Antônio de Goiás, Senador Canedo, Terezópolis de Goiás e Trindade.

Em dezembro de 2014, o Governo do Estado assinou o contrato para a elaboração do Plano de Desenvolvimento Integrado da Região Metropolitana de Goiânia (PDIRMG), coordenado pelo Instituto de Estudos Sócio-Ambientais (IESA/UFG). Em seguida, foi aprovado Estatuto da Metrópole (BRASIL, 2015), que preconiza que as regiões metropolitanas e aglomerações urbanas devem aprovar, em um prazo de até três anos (a contar da data de aprovação da lei), a instituição do Plano de Desenvolvimento Urbano Integrado. Tal ambiente propiciou novas discussões acerca da metropolização e impactos correlacionados, tais como readequações no arranjo da governança nos termos preconizados pelo Estatuto da Metrópole, sobre a descentralização da gestão e, principalmente, sobre o compartilhamento dos recursos entre os municípios da RMG. 
Em face a aprovação do Estatuto da Metrópole, e paralelamente ao desenvolvimento do PDIRMG, faz se mister uma reflexão sobre o papel da metropolização na expansão horizontal dispersa da cidade de Goiânia. Mais notadamente, no principal vetor de expansão urbana do município com ocupação predominante por condomínios horizontais fechados de alto padrão - a Região Sudeste (figura 2), área compartimentada pelas Rodovias BR-153 e GO-020, limítrofe e conurbada com os municípios de Aparecida de Goiânia e Senador Canedo, - vetor este detectado por Brito (2015) em sua dissertação de mestrado.

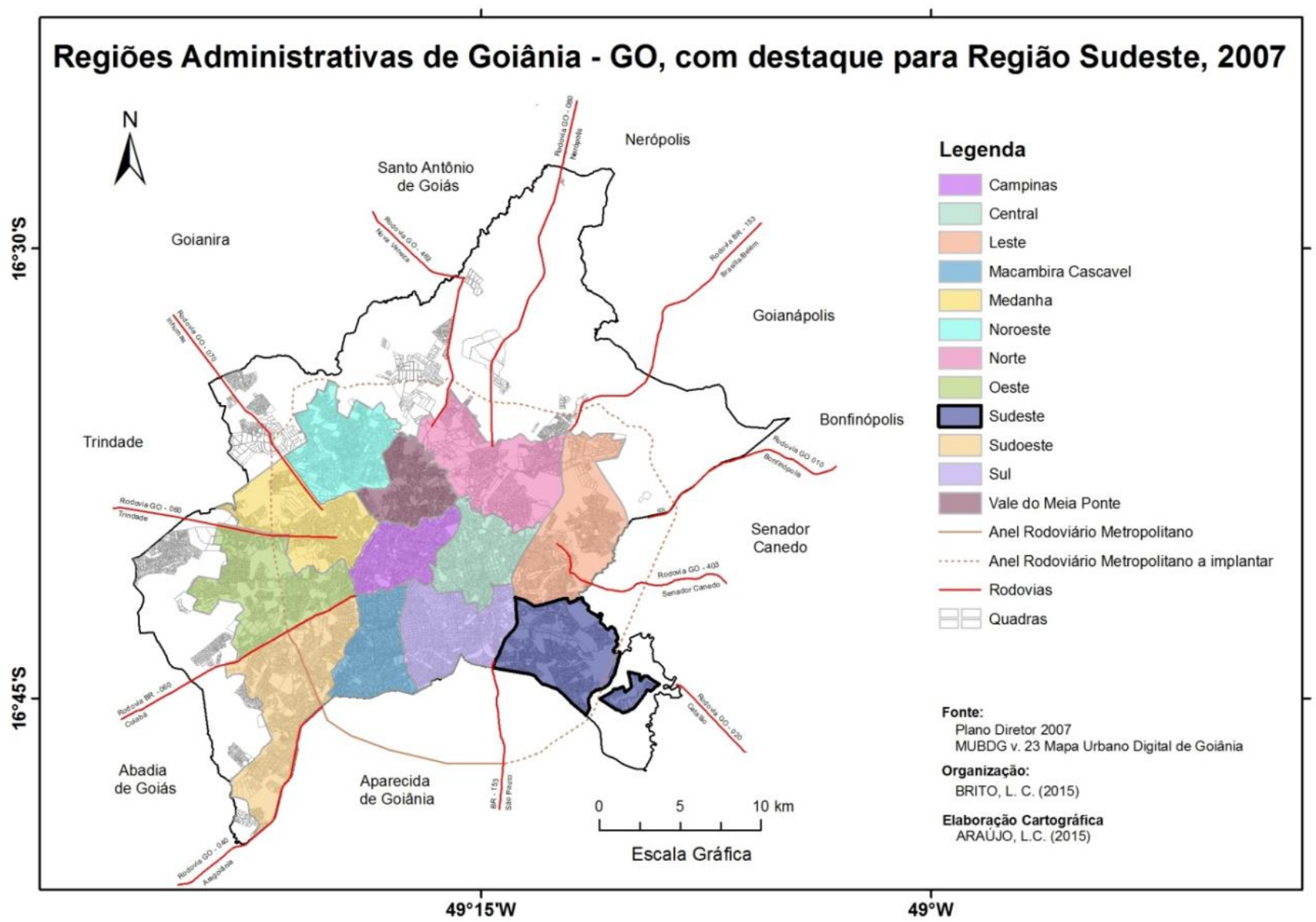

Figura 2 - Regiões Administrativas de Goiânia, com destaque para a Região Sudeste. Fonte: BRITO (2015).

Em dezembro de 2014, o Governo do Estado assinou o contrato para a elaboração do Plano de Desenvolvimento Integrado da Região Metropolitana de Goiânia (PDIRMG), coordenado pelo Instituto de Estudos Sócio-Ambientais (IESA/UFG). Em seguida, foi aprovado Estatuto da Metrópole (BRASIL, 2015), que preconiza que as regiões metropolitanas e aglomerações urbanas devem aprovar, em um prazo de até três anos (a contar da data de aprovação da lei), a instituição do Plano de Desenvolvimento Urbano Integrado. Tal ambiente propiciou novas discussões acerca da metropolização e impactos correlacionados, tais como readequações no arranjo da governança nos termos preconizados pelo Estatuto da Metrópole, sobre a descentralização da gestão e, principalmente, sobre o compartilhamento dos recursos entre os municípios da RMG.

Em face a aprovação do Estatuto da Metrópole, e paralelamente ao desenvolvimento do PDIRMG, faz se mister uma reflexão sobre o papel da metropolização na expansão horizontal dispersa da cidade de Goiânia. Mais notadamente, no principal vetor de expansão urbana do município com ocupação predominante por condomínios horizontais fechados de alto padrão - a Região Sudeste (figura 2), área compartimentada pelas Rodovias BR-153 e GO-020, limítrofe e conurbada com os municípios de Aparecida de Goiânia e Senador Canedo, - vetor este detectado por Brito (2015) em sua dissertação de mestrado.

No citado trabalho, comprovou-se que os instrumentos de gestão (compreendidos como instrumentos de regulação urbana), ao tentar qualificar e controlar os espaços da cidade em expansão, tiveram a intenção de valorizar a Região Sudeste (ver figura 3) e incorporar a ocupação das camadas de mais alta renda. Se 
inicialmente não havia uma tipologia de ocupação ${ }^{1}$ preponderante na região, iniciada na década de 1950 e até então incipiente ${ }^{2}$, à partir da década de 2000 , observou-se uma notória e predominante ocupação por condomínios horizontais fechados de alto padrão na região. Ocupação esta que por sua vez, foi propiciada pelo estoque especulativo, que havia sendo realizado, desde a década de 1950.

Observou-se que a região, uma das mais interessantes de Goiânia por conta da multiplicidade de retalhos (bairros), com formas distintas e grupos sociais bastante heterogêneos, apresenta a partir de 2000 uma ocupação homogeneizante e elitista. Ainda, se na década de 2000 ainda haviam sido detectadas extensas glebas desocupadas, passíveis de incorporação, pela imagem aérea atual constatou-se que a área já está parcelada em sua quase totalidade. Portanto, questiona-se se este vetor de expansão por condomínios horizontais fechados à sudeste, já saturado na Região Administrativa Sudeste de Goiânia e atualmente em franca direção aos municípios de Senador Canedo, é efeito ou causa da metropolização da região de Goiânia e fatores correlacionados.

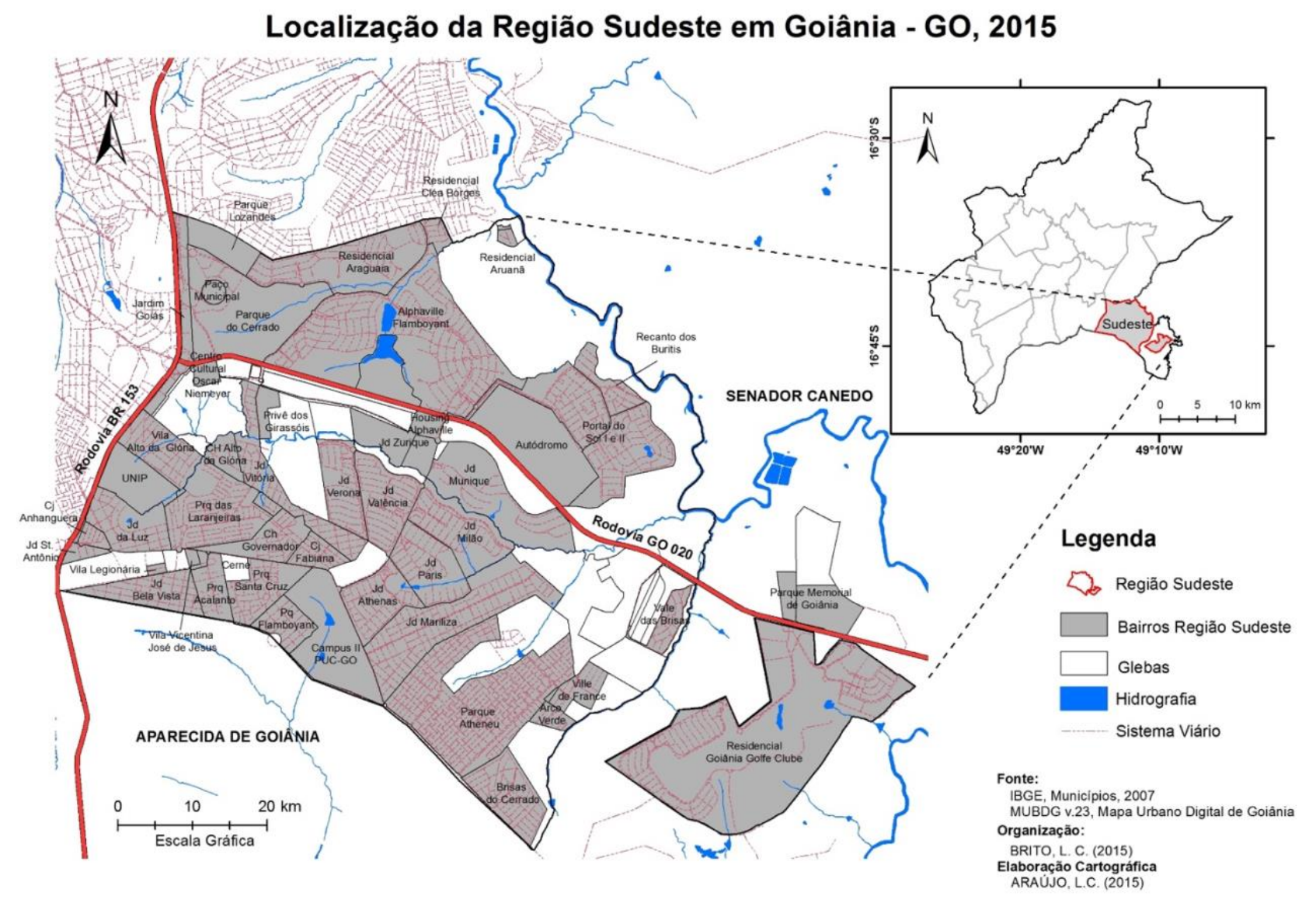

Figura 3 - Localização da Região Sudeste e principais vias de acesso. Fonte: BRITO (2015).

Kneib et al (2012) explicam o surgimento da região metropolitana a partir da polarização de uma cidadesede, que desenvolve uma relação complementar, de dependência, com outras cidades, compondo um conjunto "articulado e hierarquizado". Essa cidade, com novas características, novas funções, assume também um novo modelo espacial com identidade metropolitana, com vários núcleos, onde "existe uma população metropolitana distribuída e organizada em áreas regionais em permanente expansão" que "são amorfas na forma, maciças no escopo e hierárquicas em sua escala de organização social" (Gottdiener, 1993, p. 14).

Constata-se que os empreendedores que atuaram de forma notória na Região Sudeste, a Alphaville Urbanismo S.A e a FGR Urbanismo S.A., já iniciaram a corrida de ocupação em Senador Canedo com o

\footnotetext{
1 No citado trabalho foram detectadas as seguintes tipologias de ocupação para a Região Sudeste de Goiânia: loteamentos residenciais, conjuntos habitacionais, áreas de posse, condomínio horizontal fechado e áreas institucionais.

${ }^{2}$ A Região Sudeste é uma das 12 Regiões Administrativas de Goiânia. Não fazia do plano original da cidade até a década de 1950 , quando de área rural do município foi transformada em área de expansão urbana.
} 
lançamento de novos empreendimentos: o Terras Alpha Goiás 1 e 2 - residenciais da marca Alphaville em pleno processo de construção (acesso pelas rodovias GO-019 e GO-020, ver figura 4) e os condomínios Jardins Barcelona e Jardins Porto - ambos da FGR Urbanismo e recém-lançados (acesso pela GO-043). Essa tendência de "interiorização" dos condomínios fechados já havia sido detectado por Brito:

De acordo com reportagem do Jornal O Popular (2014c), intitulada "Condomínios ganham o interior", quase quatro mil lotes, em condomínios horizontais fechados, já foram lançados no interior goiano. Só a cidade de Anápolis já tem duas unidades Alphaville. Várias outras cidades da Região Metropolitana de Goiânia e do interior de Goiás já têm condomínios. (Brito, 2015, p. 136)

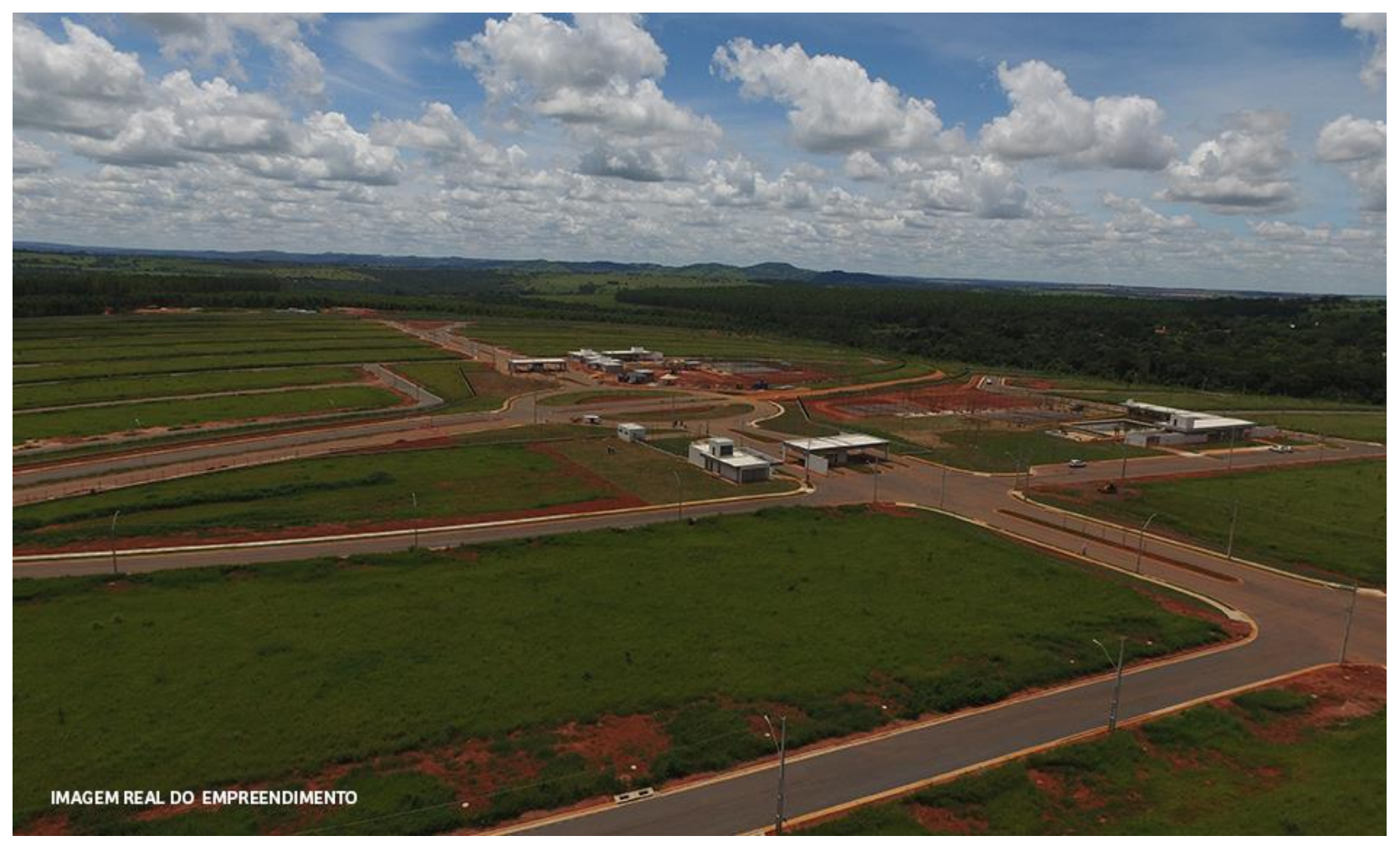

Figura 4 - Imagem do condomínio Terras Alpha em Senador Canedo. Fonte: Alphaville (2017).

\section{PROBLEMA}

A problematização envolve, a análise dos fatores que, associados à dispersão urbana, são os principais responsáveis pelo encontro do vetor de expansão à Sudeste com o município de Senador Canedo. O vetor apresenta-se singular pelo fato de que, apesar de todas as desvantagens iniciais - estar longe do centro, ser de difícil acesso e sem infraestrutura - ter sido objeto de crescentes esforços, por parte de agentes imobiliários (Estado e empreendedores imobiliários), desde o início de sua ocupação até os dias atuais. Por meio de parcerias público-privadas, tem se convertido em uma área valorizada e o principal vetor de ocupação por parte das camadas de alta renda da cidade, as quais buscam continuamente os condomínios fechados da região como opção de moradia; característica esta que se constitui na peculiaridade da área (Brito, 2015).

Questiona-se se este modelo de ocupação predominante por condomínios fechados é o mais adequado, a longo prazo, porque este padrão de urbanização causa enormes impactos, tanto em seu entorno imediato quanto na própria cidade. Tais impactos são comumente associados: a autosegregação da vida intramuros, o que gera imediações desertas, insegurança e a inibição da circulação de pedestres; ao não-diálogo com o entorno, visto que geralmente a vizinhança é mais desfavorecida economicamente e isto reforça ainda mais seu caráter exclusivista e segregador, bem como a gentrificação da população local.

Diante das considerações feitas acerca dos fatores que, associados à expansão urbana de Goiânia e sua metropolização, são os principais responsáveis pelo processo de ocupação do vetor à Sudeste por condomínios horizontais fechados, esta pesquisa se deparou com as seguintes questões: 
- Qual o contexto que propiciou o surgimento e a atual configuração do vetor de expansão à Sudeste de encontro ao município de Senador Canedo?

- Em Goiânia, assim como em tantas outras cidades, sofre-se com o "abandono" das áreas centrais, pelas camadas de alta renda da sociedade, o que pressupõe a criação de novas áreas centrais, que surgem como novo local de ação e fixação de tal classe (PAULA, 2003). Como funciona essa estratégia das camadas de alta renda, que se deslocam das áreas centrais já infraestruturadas para abrir novas frentes imobiliárias?

- Ainda nesta mesma linha de raciocínio, a Região Sudeste encontra-se plenamente incorporada e parcelada, para justificar a sua contínua expansão? Há uma demanda solvável que justifique a continuidade desta expansão em direção aos municípios vizinhos? Ou é justamente essa a estratégia dos empreendedores, a de abrir novas frentes imobiliárias em áreas que ainda sequer foram consolidadas?

- A ocupação de Senador Canedo é efeito ou causa da metropolização de Goiânia e fatores correlacionados?

\section{HIPÓTESE}

A hipótese do problema levantado, é a de que a constante busca pelos agentes imobiliários (Estado, atores do circuito comercial e proprietários de terras) de novas frentes de capital, à partir do modelo de urbanização que produz condomínios fechados, induz (ou propicia) o vetor de ocupação à Sudeste de Goiânia, de encontro ao município de Senador Canedo.

O que por sua vez foi possível em função de sua extensão territorial, em princípio constituída como área rural, concentrada nas mãos de poucos proprietários, que as utilizaram como estoque especulativo em longo prazo, visando uma valorização imobiliária que em momento oportuno, a tornasse atrativa para as camadas de mais alta renda. Este fator, além da localização rodoviária estratégica da área (entroncamento da Rodovia BR-153 com a Rodovia Estadual GO-020) - a tornam um importante eixo de escoamento da produção agrícola do estado e a principal ligação entre o centro-oeste e as regiões Norte e Sul do país, um dos fatores que determinaram e ainda determinam a sua ocupação.

\section{JUSTIFICATIVA}

A relevância do tema se justifica na medida em que o presente projeto de tese pretende abordar a temática da expansão urbana, relacionada aos instrumentos de gestão. Este assunto ainda é pouco explorado, nos estudos urbanos em Goiás. Contribuir para ampliar os estudos e pesquisas que investiguem a dinâmica metropolitana da capital do Estado de Goiás, sob a ótica da dispersão urbana aliada às estratégias do capital imobiliário também, pode permitir que seja repensado o atual processo desenfreado de expansão que a cidade vem sofrendo. Da mesma forma, vale crer que, a partir desta pesquisa, possam surgir contribuições, no sentido de melhorar o aproveitamento das potencialidades dos municípios da Região Metropolitana de Goiânia.

A aprovação do Estatuto da Metrópole (BRASIL, 2015) cuja finalidade é o estabelecimento de "um marco para a cooperação de serviços públicos comuns a diversos Municípios que integram as regiões metropolitanas" e implementação de uma política nacional de desenvolvimento metropolitano, com divisão de responsabilidades entre Estados, Municípios e União, fomentou novas questões acerca da incompatibilidade dos instrumentos de gestão urbana existentes na atualidade frente às dinâmicas e problemas típicos das Regiões Metropolitanas, problemas estes que se apresentam de forma contundente. Assim, contribuir com a apresentação de alternativas estratégicas é uma necessidade que se impõe aos pesquisadores e planejadores urbanos.

Pretende-se, ainda, apresentar a análise da lógica da produção das cidades como um excedente, que necessita da urbanização para absorver o produto que gera continuamente. Ou seja, procurar compreender a lógica entre o desenvolvimento do capitalismo e a sua relação com o processo de urbanização na Região Metropolitana de Goiânia, mais notadamente no Vetor à Sudeste. 


\section{OBJETIVOS GERAL E ESPECÍFICO}

O objetivo geral é demonstrar a partir de uma reflexão teórica, como se formou o principal vetor de expansão urbana da RMG por condomínios fechados à Sudeste e comprovar que ele está avançando de encontro ao município limítrofe, no caso Senador Canedo. Já os específicos são: analisar e documentar como se deu a formação do vetor à Sudeste no contexto da RMG e apresentar o processo de urbanização por condomínios fechados frente à lógica do capital que trata a cidade como mercadoria e a sua expansão como excedente de produção.

\section{METODOLOGIA DE PESQUISA: PLANO DE TRABALHO}

O objetivo geral é demonstrar a partir de uma reflexão teórica, como se formou o principal vetor de expansão urbana da RMG por condomínios fechados à Sudeste e comprovar que ele está avançando de encontro ao município limítrofe, no caso Senador Canedo. Já os específicos são: analisar e documentar como se deu a formação do vetor à Sudeste no contexto da RMG e apresentar o processo de urbanização por condomínios fechados frente à lógica do capital que trata a cidade como mercadoria e a sua expansão como excedente de produção.

Sob o ponto de vista de sua abordagem, esta pesquisa utiliza, inicialmente o método hipotético-dedutivo, que parte de um problema, ao qual se oferece uma hipótese provisória, que deverá ser comprovada, com vista a eliminação do erro (Marconi, Lakatos, 2003). Já em relação aos seus objetivos, trata-se de pesquisa exploratória, de forma a reunir maiores informações sobre o assunto escolhido, possibilitando sua melhor definição e delineamento, além de facilitar a delimitação do tema.

Do ponto de vista dos procedimentos técnicos, esta pesquisa adota o estudo de caso, envolvendo o estudo do recorte espacial, permitindo o seu amplo e detalhado conhecimento. Define-se, também, um estudo de caso como uma estratégia de pesquisa que busca examinar um fenômeno contemporâneo dentro de seu contexto. Procura-se analisar o vetor de expansão à Sudeste de Goiânia, no contexto da dispersão urbana e metropolização da cidade. Registra-se a necessidade de alguns requisitos básicos para sua realização, entre os quais, a severidade, a objetivação, a originalidade e a coerência.

Têm-se como proposta metodológica de pesquisa:

1. Introdução, problema, hipótese, objetivos;

2. Referencial teórico, englobando os temas:

a) Ação dos agentes sociais e processos espaciais;

b) Dispersão Urbana;

c) Condomínios fechados;

d) Relação entre o Capital e a Urbanização;

e) Metropolização.

3. Desenvolvimento de Metodologia de análise para realização da Pesquisa (estudo de caso):

a) Análise espaço-temporal da expansão urbana metropolitana (2000-2020);

b) Realização de estudo de expansão, por décadas (loteamentos regulares e irregulares);

c) Estudo das tipologias dos loteamentos;

d) Localização dos condomínios fechados, datas de aprovação, implantação e ocupação.

4. Considerações finais

5. Referências bibliográficas.

\subsection{Fontes de pesquisa (primária e secundária)}

Para complementação dos dados, utiliza-se: 
a) Fontes de pesquisa primária:

- dissertação de mestrado: BRITO, L. C. A Expansão Urbana de Goiânia e Instrumentos de Gestão: Um Enfoque sobre a Região Sudeste. 161p. Faculdade de Artes Visuais, Universidade Federal de Goiás, Goiânia, 2015.

- capítulo de livro: BRITO, L. C.; KNEIB, E. C. Impactos de Áreas de Expansão Urbana na Mobilidade e Acessibilidade: A Região Sudeste de Goiânia. In: Projeto e Cidade: Mobilidade e Acessibilidade em Goiânia. Goiânia: UFG, 2016, v.1, p. 95-112;

- artigo: BRITO, L. C. A Abordagem Tipológica como estratégia de compreensão do tecido urbano: o caso da Região Sudeste de Goiânia. In: Anais da 4ª Conferência do PNUM Morfologia Urbana e os Desafios da Urbanidade. Brasília - DF, 2015.

b) Fontes de pesquisa secundária:

- Ação dos agentes sociais e processos espaciais: CORRÊA (1989), HARVEY (1982) e (2013) e LEFÉBVRE, (1976);

- Dispersão Urbana: ESPAÑA (1991), GONZALEZ et al (2013), LEFEBVRE (1999), PESCATORI, ABREU (2016), REIS FILHO (2006) e VALE, GERARDI (2006);

- Condomínios fechados: CALDEIRA (2000), FERNANDES (2013) e PESCATORI, ABREU (2016);

- Relação entre o Capital e a Urbanização: FERNANDES (2013), HARVEY (2013);

- Metropolização: ARRAIS (2013), BARREIRA (2013), VILLAÇA (2001) e relatórios parciais do Plano de Desenvolvimento Integrado da RMG em desenvolvimento pelo IESA/UFG.

\section{REVISÃO BIBLIOGRÁFICA}

\subsection{Ação dos agentes sociais e processos espaciais}

A cidade é a expressão concreta dos processos sociais na forma de ambiente físico construído sobre um espaço geográfico. O estudo da cidade e dos processos sócio-espaciais que lhe conferem sua organização e sua configuração interessa a todos, desde os que atuam e investem na cidade, bem como aos estudiosos que a analisam, assim como aos habitantes deste complexo espaço. De acordo com Corrêa (1989), o espaço urbano capitalista - fragmentado, articulado, reflexo, condicionante social, cheio de símbolos e campo de lutas - é um produto social, resultado de ações acumuladas através do tempo, e engendradas por agentes que produzem e consomem o espaço. Corrêa (1989) classifica os agentes em: a) os proprietários dos meios de produção, sobretudo os grandes industriais; b) os proprietários fundiários; c) os promotores imobiliários; d) o Estado; e) os grupos sociais excluídos.

Em primeiro lugar, a ação desses agentes se faz dentro de um marco jurídico que regula a atuação deles (não-neutro e refletindo o interesse dominante de um agente). Em segundo lugar, há denominadores comuns que unem os três primeiros agentes (os proprietários dos meios de produção, os proprietários fundiários e os promotores imobiliários), exemplo é a apropriação da renda da terra. Ou seja, o espaço urbano constitui-se instrumento, através da posse e do controle do uso da terra urbana (Lefebvre, 1976). Em terceiro lugar o atual estágio do capitalismo por vezes promove uma integração em que muitos dos conflitos que poderiam haver entre os agentes desaparecem. Em quarto lugar, é importante notar que as estratégias que esses agentes adotam variam no tempo e espaço. Ainda, dos processos espaciais estudados por Corrêa, interessa-nos a descentralização e a segregação.

Cabe reafirmar que a oposição fundamental que se retrata no espaço urbano é a que se estabelece entre capital e trabalho. No entanto as contradições existentes entre as diversas frações do capital e os diferentes segmentos da população em relação ao uso do solo também interferem na configuração espacial da cidade.

Para Harvey (1982), vários atores, representantes de diferentes interesses, estão envolvidos em fortes conflitos que têm por palco o urbano: os proprietários de terra e as empresas imobiliárias, cujo objetivo é a apropriação direta de renda; os intermediários financeiros que indiretamente visam a obter taxas de retorno 
para suas aplicações dirigidas à área de negócios imobiliários; o setor da construção civil, buscando lucros através dos seus empreendimentos; o capital "em geral" que tem no espaço urbano as condições para produção e acumulação; e a força de trabalho, para quem a cidade significa meio de consumo e meio de reprodução.

\subsection{Dispersão Urbana}

Quando se analisa o crescimento urbano brasileiro e mundial, logo é possível constatar que o mesmo alcança uma inédita proporção, levando as cidades a expandirem seus limites físicos sobre o espaço rural, o qual possui identidade própria, um modo de vida e de organização econômica distinto do espaço urbano (Vale, Gerardi, 2006). Este fenômeno, denominado por Lefebvre (1999) de "implosão-explosão" (metáfora tomada da física nuclear), é seguido pela fragmentação, homogeneização e hierarquização do espaço.

Segundo España (1991), tal processo tem como consequência a integração do espaço rural pela cidade, podendo ocorrer por meio de duas etapas distintas: a do crescimento compacto, em forma de anéis concêntricos, invadindo os espaços mais próximos e os integrando à economia urbana; e a da urbanização de áreas mais distantes (dezenas de quilômetros). A essa segunda forma de urbanização se denomina de difusa ou dispersa.

No presente estudo, portanto, particularmente interessam-nos os fenômenos relacionados à dispersão urbana e seus desdobramentos no espaço urbano. De acordo com Reis Filho (2006) as principais características da urbanização dispersa são: (1) descentralização da população, do emprego e dos serviços; (2) produção de "novas periferias"; (3) extensão da área urbanizada por vasto território, separadas fisicamente, mas fortemente interdependentes, formando um sistema urbano único; (4) desenvolvimento de novos modos de vida, viabilizados pela maior mobilidade (especialmente a individual), "organizando seu cotidiano em escala metropolitana e inter-metropolitana, envolvendo diversos municípios"; (5) novas formas de organização urbanística: condomínios e loteamentos fechados, empreendimentos de usos múltiplos isolados, shoppings centers - alteração das relações público - privado.

São notáveis no vetor em estudo os itens 4 e 5. Brito, Kneib (2016) ao analisar o número de viagens diárias geradas no vetor nos últimos 10 anos, observaram um aumento médio de $60 \%$ no número de viagens geradas por veículo motorizado individual, seguido pelo transporte coletivo e pelo modo a pé (ver figura 5). Certamente causados pelas novas formas de urbanização detectados e já supracitados (condomínios fechados, shopping centers, entre outros).

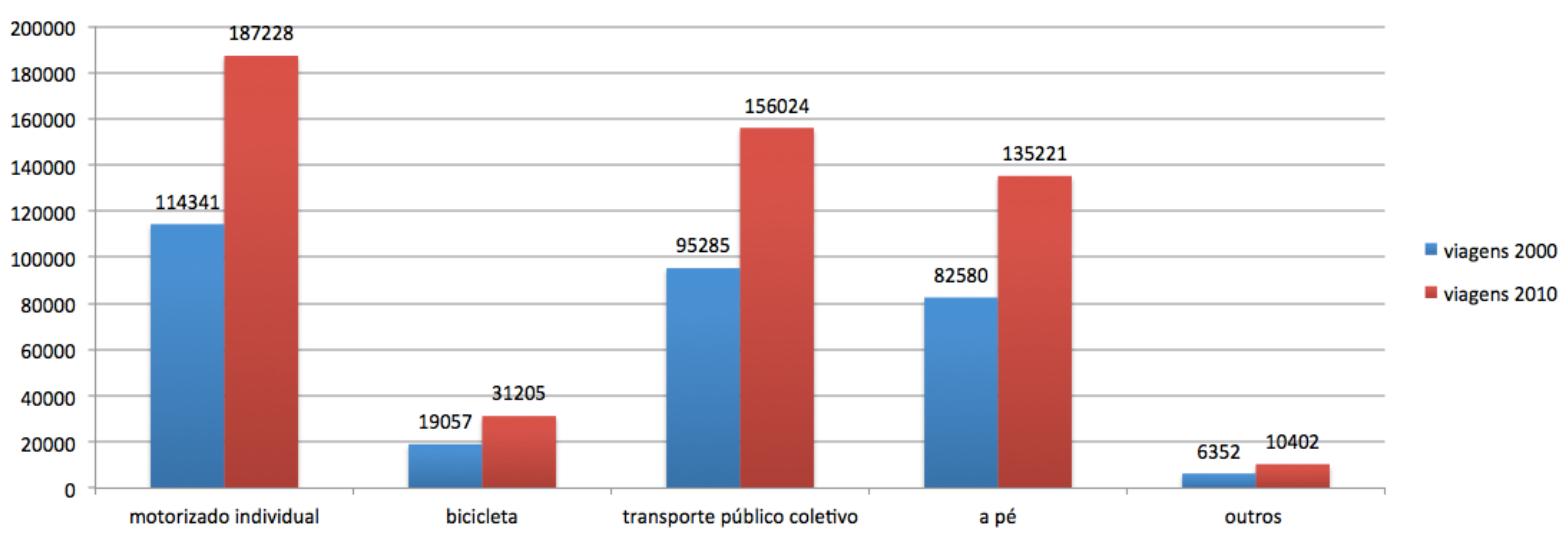

Figura 5 - Estimativa do número de viagens diárias geradas, por modo, nos períodos analisados. Fonte: BRITO, KNEIB (2016).

\subsection{Condomínios fechados}

Dentre todas as formas de organização espacial características da dispersão urbana acima identificadas, o condomínio horizontal e os loteamentos fechados são as mais conhecidas (e questionadas) deste processo no Brasil. A antropóloga Teresa Caldeira, enumera as principais características da categoria de urbanização 
que ela denomina de "enclaves fortificados", e inclui shopping centers, conjuntos de escritórios, condomínios fechados verticais (de edifícios), mas também os condomínios horizontais (Caldeira, 2000).

Esta nova forma de organização urbanística - o condomínio fechado, também é estudada por Pescatori, Abreu (2016). Para os autores, sua popularização deveu-se à atuação urbanística da Alphaville Urbanismo S.A. e argumentam que ela exerceu, e permanece exercendo, papel fundamental na configuração da cidade contemporânea brasileira, por meio de: 1) difusão de um tipo de urbanização - o condomínio residencial horizontal fechado, contribuindo para a configuração - cada vez mais homogênea e similar - da paisagem das cidades brasileiras; 2) o estabelecimento de um padrão urbanístico e gerencial assimilado por outros empreendimentos e empresas urbanizadoras em todo o país; 3) ampliação da atuação de empresas privadas de urbanização, que antes era responsável por construir partes da cidade de acordo com planos e projetos governamentais, e passa a determinar pontos fundamentais do planejamento urbanístico, construindo cidades inteiras.

Fernandes (2013) aponta ainda duas questões nevrálgicas a respeito das relações que se estabelecem na implementação desses empreendimentos corporativos: em primeiro lugar, do ponto de vista da negociação para a liberação dos mesmos, parece incidir uma grande assimetria de poder entre o público e o privado, estando o público muitas vezes refém da pressão pela criação de empregos e crescimento econômico e da ameaçadora competição entre lugares. Há também situações em que o poder público é francamente aderente a essa forma de condução da produção da cidade. Em segundo lugar, do ponto de vista da produção dos espaços, a segregação social e espacial é uma de suas marcas. É um urbanismo contra a cidade. Enquanto condomínios fechados, o desenho é em geral pensado para negar o entorno e o contexto, com pouquíssimas relações com as áreas ou bairros circunvizinhos, inclusive do ponto de vista da articulação da malha urbana.

A implantação do primeiro condomínio fechado de alto padrão na Região Sudeste em 2000 - o Alphaville Flamboyant, coincide com a fase em que a empresa iniciou a sua expansão em solo nacional, pois até então, a sua atuação estava restrita à Região Sudeste do país. O que corrobora a opção de análise pelo recorte espaço-tempo de 2000 à 2020. Em face os apontamentos realizados por Fernandes (2013), parece uma opção natural aos empreendedores que atuam na Região Sudeste, avançar pelas cidades limítrofes à Goiânia - cidades menores, com prefeituras ávidas por investimentos e novas fontes de arrecadação fiscal e geralmente sem os entraves e a burocracia das quais os municípios maiores não podem se desvencilhar.

\subsection{Relação entre o Capital e a Urbanização}

No presente trabalho, busca-se também, compreender a estratégia que trata a cidade como mercadoria e que, portanto, visa ao lucro fácil e sem compromisso com os impactos relacionados à este modo de urbanização. Para Harvey (2013, p.42) a urbanização tem sido um dos principais meios para a absorção de capital e de excedentes de trabalho através da história do capitalismo. Ela tem uma função muito particular na dinâmica da acumulação do capital em função de longos períodos de trabalho e tempos de rotação dos investimentos no ambiente construído. Isso tem também uma especificidade geográfica de tal modo que a produção do espaço e de monopólios espaciais torna-se essencial à dinâmica da acumulação, não apenas pela mudança dos padrões dos fluxos de mercadorias no espaço, mas também pela natureza mesma dos espaços e lugares criados e produzidos sobre os quais esses movimentos ocorrem.

A esse respeito Santos (2002, p.61-64 apud Fernandes 2013, p.84) afirma que a expansão das cidades por extensão, contínua ou dispersa, ancorada nos vazios urbanos - lote sou glebas deixados vagos à espera de valorização - combinam-se, crescentemente, a expansão urbana por sobreposição e densificação de áreas já ocupadas e o abandono de regiões urbanas inteiras, muitas delas precocentemente tornadas obsoletas. Fundamentam essa obsolescência as novas lógicas de produção e especulação imobiliária e financeira, os requistos tecnológicos e de cooperação das atividades econômicas e a incongruência entre o que se constrói e as carências sociais existentes. Às situações urbanas e esvaziadas resultantes desse processo chamamos de vazios construídos, onde áreas inteiras das cidades perdem função ou vitalidade, ou, de forma ainda mais dramática, já são construídas enquanto áreas que não conseguem ser preenchidas por dinâmica social ou urbana.

\subsection{Metropolização}

A região do Entorno de Goiânia passou por mudanças profundas nos últimos anos nos aspectos: territorial, social, econômico, ambiental e político. Destacando no contexto, o inchaço populacional, que resultou na 
segregação urbana, deterioração do centro da capital e de sua periferia, déficit habitacional, entre outros. Além dos fatores acima elencados, Goiânia e seu entorno cresceu de forma espraiada, o que dificulta a implantação de estratégias de desenvolvimento urbano e regional.

Neste contexto, observa-se que os municípios de Senador Canedo, Aparecida de Goiânia, Trindade e Goianira são os que, até o momento, sofreram a maior influência do processo de metropolização de Goiânia através de um processo de conurbação prematuro e intenso.

A dinâmica populacional das últimas décadas do século $X X$ também provocou a conurbação induzida $e$ forçada rumo aos citados municípios. Essa dinâmica é alimentada pelo déficit habitacional, pela exclusão social e potencializada pela especulação imobiliária. Observa-se ainda que As áreas rurais na margem da metrópole estão sendo transformadas em reservas de valor em loteamentos urbano sem ocupação, os chamados vazios urbanos. Além de um acentuado crescimento nos índices de violência e criminalidade na Região (Barreira, 2013).

\section{METODOLOGIA}

Ao se realizar um estudo de caso, o pesquisador deve cercar-se de rigor metodológico e ser cuidadoso com uma possível fragilização da explicação científica, em função de incidências de fenômenos encontrados, somente, no universo pesquisado. Deve-se, portanto, compor um cenário que corresponda à teoria que fundamenta a pesquisa, e que se revele no decorrer do estudo do caso. Melhor dizendo, é preciso que se construa uma análise que explique e preveja o fenômeno investigado. Por fim, o pesquisador deve estar atento ao tempo destinado à pesquisa, observando o fato de que os estudos de caso não precisam, necessariamente, demorar muito tempo. (Prodanov, Freitas, 2013)

Portanto, pretende-se a: realização de estudo de expansão, por décadas (loteamentos regulares e irregulares); o estudo da tipologia dos loteamentos; a localização dos condomínios fechados, datas de aprovação, implantação e ocupação.

Para complementação dos dados, utiliza-se:

- A elaboração de mapas visando explorar as potencialidades do Sistema de Informações Geográficas (SIG), como ferramenta de análise dos fenômenos acerca do recorte espaço- temporal investigado (Vetor de Expansão à Sudeste 2000-2020), para que, além da percepção visual da distribuição espacial do problema, que os padrões encontrados possam ser traduzidos em considerações objetivas e mensuráveis;

- Pesquisa de campo: relatos dos moradores, demais pesquisadores e pessoas que guardam a memória oral da evolução histórica da região.

\section{REFERÊNCIAS}

ARRAIS, T. A. (2013). A Produção do Território Goiano: Economia, Urbanização, Metropolização. Goiânia: Editora UFG.

BARREIRA, C. C. M. A. (2013). Ocupação e uso do espaço em Região Metropolitana - produção de informações e subsidios analíticos para elaboração do plano diretor de desenvolvimento integrado - PDDI. Goiânia: Universidade Federal de Goiás.

BRASIL (2015) Lei 13.089, de 12 de janeiro de 2015. Institui o Estatuto da Metrópole, altera a Lei 10.257, de 10 de julho de 2001, e dá outras providências.

BRITO, L. C. (2015). A Expansão Urbana de Goiânia e Instrumentos de Gestão: Um enfoque sobre a Região Sudeste. 161p. Dissertação (Mestrado em Projeto e Cidade) - Faculdade de Artes Visuais, Universidade Federal de Goiás, Goiânia. 
BRITO, L. C., KNEIB E. C. (2016). Impactos de áreas de expansão urbana na mobilidade e acessibilidade: a Região Sudeste de Goiânia. (pgs. 95 a 102) In: KNEIB E. C. (Org.). Projeto e cidade : mobilidade e acessibilidade em Goiânia. Goiânia: Editora UFG.

CALDEIRA, T. P. R. (2000). Cidade de muros: crime, segregação e cidadania em São Paulo. São Paulo: EDUSP; Editora 34.

CASTELLS, M. (1999). A sociedade em rede. Rio de Janeiro: Paz e Terra.

CORRÊA, R. L. O (1989). Espaço Urbano. São Paulo: Editora Ática S.A.

ESPAÑA, E. D. (1991) La agricultura en espacios periurbanos en el municipio de Alboraya. Valencia: Universidad de Valencia.

FERNANDES, A. (2013). Decifra-me ou te devoro: urbanismo corporativo, cidade-fragmento e dilemas da prática do urbanismo no Brasil. (pgs. 83 a 108) In: Gonzalez, S. F. N., Paviani, A., Francisconi, J.G. Planejamento e Urbanismo na atualidade brasileira: objeto teoria prática. São Paulo: Rio de Janeiro: Livre Expressão.

GOTTDIENER, M. (1993). A produção social do espaço urbano. Trad. Geraldo Gerson de Souza. São Paulo: Edusp.

HARVEY, D. (1982). O trabalho, o capital e o conflito de classes em torno do ambiente construído nas sociedades capitalistas avançadas. Espaço e Debates, São Paulo, Cortez, 2(6):7, jun./set. 1982.

(2013). Ciudades rebeldes: Del derecho de la ciudad a la revolución urbana. Tradução de Juanmari Madariaga. Madri: Akal.

KNEIB, E. C. et al. (2012). PGVs e Centralidades: Impactos na Escala Urbana e Metropolitana. In: PORTUGAL, L. da S. Polos Geradores de Viagens orientados à qualidade de vida e ambiental. Rio de Janeiro: Editora Interciencia.

LEFÉVBRE, H. (1976). Espacio y politica. Barcelona: Ediciones Peninsula.

(1999). A revolução Urbana. Belo Horizonte: UFMG.

MARCONI, M. A.; LAKATOS, E. M. (2003). Fundamentos da Metodologia Científica. São Paulo: Atlas S.A.

PAULA, F. M. de A. (2003). Descentralização e segregação sócio-espacial em Goiânia: uma análise da centralidade dos setores Bueno, Oeste e Marista. Dissertação (Mestrado em Geografia). Instituto de Estudos Sócio-Ambientais. Universidade Federal de Goiás. Goiânia.

PESCATORI, C. ABREU, L. (2016). Da construtora Albuquerque e Takaoka à Alphaville Urbanismo S.A.: reestruturação e expansão nacional de um modelo de urbanização. Anais do IV ENANPARQ: Encontro da Associação Nacional de Pesquisa e Pós-Graduação em Arquitetura e Urbanismo. Porto Alegre. 
PRODANOV, C. C., FREITAS, E. C. de (2013). Metodologia do trabalho científico [recurso eletrônico]: métodos e técnicas da pesquisa e do trabalho acadêmico. $2^{2}$ edição. Novo Hamburgo: Feevale.

REIS FILHO, N. G. (2006). Notas sobre urbanização dispersa e novas formas de tecido urbano. São Paulo: Via das Artes.

VALE, A. R.; GERARDI, L. H. O. (2006). Crescimento urbano e teorias sobre o espaço periurbano: analisando o caso do Município de Araraquara (SP), em Geografia: ações e reflexões (pg. 231-246).

VILLAÇA, F. (2001). Espaço intra-urbano. São Paulo: Studio Nobel.

\section{Fontes eletrônicas:}

http://www.alphaville.com.br/ (Consulta: 16/09/2017).

http://www.imb.go.gov.br/ (Consulta: 29/09/2017). 